\title{
Gravimetric recovery of the Moho geometry based on a generalized compensation model
}

\author{
Robert TENZER ${ }^{1}$ \\ ${ }^{1}$ The Key Laboratory of Geospace Environment and Geodesy \\ School of Geodesy and Geomatics, Wuhan University \\ 129 Luoyu Road, Wuhan, 430079 China; e-mail: rtenzer@sgg.whu.edu.cn
}

\begin{abstract}
Gravity data used for a recovery of the Moho depths should (optimally) comprise only the gravitational signal of the Moho geometry. This theoretical assumption is typically not required in classical isostatic models, which are applied in gravimetric inverse methods for a recovery of the Moho interface. To overcome this theoretical deficiency, we formulate the gravimetric inverse problem for the consolidated crust-stripped gravity disturbances, which have (theoretically) a maximum correlation with the Moho geometry, while the gravitational contributions of anomalous density structures within the lithosphere and sub-lithosphere mantle (including the core-mantle boundary) should be subtracted from these gravity data. In the absence of a reliable 3-D Earth's density model, our definitions are limited to the crustal and upper mantle density structures. The gravimetric forward modeling technique is applied to compute these gravity data using available models of major known anomalous crustal and upper mantle density structures. The gravimetric inverse problem is defined by means of the (non-linear) Fredholm integral equation of the first kind. After linearization of the integral equation, the solution to the gravimetric inverse problem is given in a frequency domain. The inverse problem is formulated for a generalized crustal compensation model. It implies that the compensation equilibrium is (theoretically) attained by both, the variable depth and density of compensation. A theoretical definition of this generalized crustal compensation model and a formulation of the gravimetric inverse problem for finding the Moho depths are given in this study.
\end{abstract}

Key words: crust, gravimetric methods, gravity, Moho interface

\section{Introduction}

The results of seismic surveys have been primarily used in global and regional geophysical studies investigating the lithosphere structure. Soller et 
al. (1982) derived the global Moho seismic model with a $2 \times 2$ arc-deg spatial resolution. The global Moho model compiled with a spectral resolution complete to degree 30 of spherical harmonics was presented by $\check{C}$ adek and Martinec (1991). Shapiro and Ritzwoller (2002) and Meier et al. (2007) compiled the global Moho models also based purely on seismic data analysis. Nataf and Ricard (1996) derived the global model of the crust and upper mantle density structures based on the analysis of seismic data and additional constraining information such as heat flow and chemical composition. For global studies the most often used (publically available) global crustal model is the CRUST2.0 (Bassin et al., 2000). The CRUST2.0 model contains information on the crustal density structure including the upper mantle. The CRUST2.0 is an upgrade of the CRUST5.1 (Mooney et al., 1998). Both these models were compiled based on seismic data published until 1995 and a detailed compilation of ice and sediment thickness. The globally averaged data from active seismic methods and deep drilling profiles were used to predict the crustal structure where no seismic measurements were available (most of Africa, South America, Greenland and large parts of oceans) by a generalization to similar geological and tectonic settings (see e.g., Tsoulis, 2004). The CRUST1.0 is the latest version, compiled with a $1 \times 1$ arc-deg spatial resolution.

Over large areas of the world with a sparse coverage of seismic data, the gravimetric or combined gravimetric/seismic methods are applied. In gravimetric studies of the isostasy, two basic concepts have been commonly adopted, assuming that the topographic mass surplus and the oceanic mass deficiency are compensated either by a variable depth or density of compensation. The Pratt-Hayford isostatic model is based on adopting a constant depth of compensation while considering a variable density contrast (Pratt, 1855; Hayford, 1909; Hayford and Bowie, 1912). In the Airy-Heiskanen isostatic model a constant density contrast is assumed while a depth of compensation is variable (Airy 1855; Heiskanen and Vening Meinesz, 1958). Vening Meinesz (1931) modified the Airy-Heiskanen theory by introducing a regional isostatic compensation based on a thin plate lithospheric flexure model (cf. Watts, 2001). Results of seismic studies acquired that the continental crust has a typical thickness of about 30 to $50 \mathrm{~km}$ with the largest crustal thickness (up to $\sim 80 \mathrm{~km}$ ) along the convergent tectonic plate boundaries in the Andes (i.e., the ocean-to-continent subduction zone) and in the 
Himalayas (i.e., the continent-to-continent collision zone) extending beneath the Tibet Plateau. The oceanic crustal thickness is typically between 5 and $15 \mathrm{~km}$ (cf. Bassin et al., 2000). These large variations in the crustal thickness as well as a general agreement between the crustal thickness estimated from seismic and gravity surveys more or less support the Airy-Heiskanen and Vening Meinesz theories of isostasy. According to the Airy-Heiskanen theory of a local compensation, there is no correlation between neighboring crustal columns. However, it is well known that the isostatic compensation is valid only at long wavelengths due to rigidity of the elastic lithosphere and viscosity of the asthenosphere, which are approximated more realistically by the Vening Meinesz isostatic model based on a regional compensation mechanism. In regional models the compensating masses are distributed laterally. To achieve this Vening Meinesz (1931) assumed that the crust is a homogeneous elastic plate floating on a viscous mantle. The regional compensation model was later adopted in the Parker-Oldenburg isostatic method (Oldenburg, 1974). A similar method based on the iterative 3-D gravity inversion with integration of seismologic data was developed and applied by Braitenberg and Zadro (1999). Moritz (1990) utilized the Vening Meinesz inverse problem in solving the isostatic-gravimetric model for estimating the Moho depths. The methods of Parker-Oldenburg and Moritz are very similar. In fact both these models use the interface detection theory (Dorman and Lewis, 1970). It implies that the Bouguer gravity anomaly relates to elevation/depth at a certain position. Sjöberg (2009) formulated Moritz's problem, called herein the Vening Meinesz-Moritz (VMM) problem of isostasy, as that of solving a non-linear Fredholm integral equation of the first kind. Sampietro et al. (2013) developed the method for the Moho recovery using the GOCE gravity gradient data; see also Braitenberg et al. (2010) and Sampietro (2011).

The isostatic mass balance depends on loading and effective elastic thickness, rigidity, rheology of the lithosphere and viscosity of the asthenosphere (see e.g., Watts, 2001). Moreover, geodynamic processes such as the glacial isostatic adjustment, present-day glacial melting, plate motion and mantle convection contribute to the time-dependent isostatic balance. The classical isostatic models are typically not able to model realistically the actual Moho geometry without using additional constraining information (mainly from results of seismic surveys). Moreover, seismic studies revealed that the 
Moho depth and density contrast vary significantly (cf. Geiss, 1987; Martinec, 1994; Kaban et al., 2003; Sjöberg and Bagherbandi, 2011). A possible way to partially overcome theoretical limitations of classical isostatic models is to use these models for different areas of the world based on the expectation that a particular isostatic model would better reproduce the reality. Following this principle, Wild and Heck (2004) and Makhloof (2007) applied the Airy-Heiskanen model over continents and the Pratt-Hayford model over oceans. Sjöberg and Bagherbandi (2011) proposed a more generalized concept. They developed and applied a least-squares approach, which combined seismic and gravity data in the VMM isostatic inverse scheme for a simultaneous estimation of the Moho depth and density contrast. They also presented and applied the non-isostatic correction to model for discrepancies between the isostatic and seismic models (cf. Bagherbandi and Sjöberg, 2012).

In gravimetric studies the anomalous density structure not only within the crust but essentially within the whole lithosphere should be modeled (cf. Kaban et al., 1999, 2004; Tenzer et al., 2009a; 2012a). Moreover, large portion of the isostatic mass balance is attributed to variable sublithosphere mantle density structure, which has significant effect especially on a long-wavelength part of the isostatic gravity spectra and consequently on the respective Moho geometry (cf. Sjöberg, 2009). The gravitational field generated by all known anomalous density structures should be modeled and subsequently removed from observed gravity field in prior of solving the gravimetric inverse problem. One example can be given in Greenland and Antarctica where the application of the ice (density contrast) stripping correction to gravity data is essential for a realistic interpretation of gravimetric results. Another significant gravitational contribution to be modelled and subsequently subtracted from gravity data is due to large sedimentary basins. Braitenberg et al. (2006) and Wienecke et al. (2007), for instance, demonstrated that the misfit of the isostatic assumption of the Moho interface to a long-wavelength part of the gravity field is explained by large sedimentary basins and rigidity variations of the crustal plate.

In this study, the gravimetric inverse problem for finding the Moho depths is formulated for a generalized crustal compensation model. This compensation model assumes that the isostatic mass balance within the crust is attained not only by a variable depth of compensation (i.e., vari- 
able Moho depth), but also a variable density of compensation (i.e., variable Moho density contrast). It is further assumed that the (lateral) Moho density contrast is known from available models of the crustal and upper mantle structures. The application of the developed numerical approach on synthetic or real data is out of the scope of this study.

\section{Functional model}

We formulate a functional model between the (given) consolidated cruststripped gravity disturbances $\delta g^{c s}$ and the (unknown) Moho depths $D$ (by means of Newton's volumetric integral) in the following form

$\delta g^{c s}(r, \Omega)=-\mathrm{G} \iint_{\Omega^{\prime} \in \Phi} \Delta \rho^{\mathrm{c} / \mathrm{m}}\left(\Omega^{\prime}\right) \int_{r^{\prime}=\mathrm{R}-D\left(\Omega^{\prime}\right)}^{\mathrm{R}} \frac{\partial \ell^{-1}\left(r, \psi, r^{\prime}\right)}{\partial r} r^{\prime 2} \mathrm{~d} r^{\prime} \mathrm{d} \Omega^{\prime}$,

where $\mathrm{G}=6.674 \times 10^{-11} \mathrm{~m}^{3} \mathrm{~kg}^{-1} \mathrm{~s}^{-2}$ is Newton's gravitational constant; $\mathrm{R}=6371 \times 10^{3} \mathrm{~m}$ is the Earth's mean radius; $\Delta \rho^{\mathrm{c} / \mathrm{m}}$ is the (laterally varying) Moho density contrast (in $\mathrm{kg} \mathrm{m}^{-3}$ ); $\ell$ is the Euclidean spatial distance of two points $(r, \Omega)$ and $\left(r^{\prime}, \Omega^{\prime}\right) ; \psi$ is the respective spherical distance; and $d \Omega^{\prime}=\cos \phi^{\prime} d \phi^{\prime} d \lambda^{\prime}$ is the infinitesimal surface element on the unit sphere. The 3 -D position is defined in the spherical coordinate system $(r, \Omega)$; where $r$ is the spherical radius, and $\Omega=(\phi, \lambda)$ denotes the spherical direction with the spherical latitude $\phi$ and longitude $\lambda$. The full spatial angle is denoted as $\Phi=\left\{\Omega^{\prime}=\left(\phi^{\prime}, \lambda^{\prime}\right): \phi^{\prime} \in[-\pi / 2, \pi / 2] \wedge \lambda^{\prime} \in[0,2 \pi)\right\}$. The unknown parameter in Eq. (1) is the Moho depth $D^{\prime}$, while it is assumed that the laterally varying Moho density contrast $\Delta \rho^{\mathrm{c} / \mathrm{m}}$ is a priori known (for instance, from results of seismic surveys). The consolidated crust-stripped gravity disturbances $\delta g^{c s}$ on the left-hand side of Eq. (1) are obtained from the gravity disturbances $\delta g$ after applying the topographic and stripping gravity corrections of major known anomalous crustal density structures. The reasons of facilitating gravity disturbances instead of more commonly used gravity anomalies were discussed in detail by Vajda et al. (2007).

The numerical procedures applied in the gravimetric forward modeling of these gravity corrections were given in Tenzer et al. (2008; 2009a; 2010a; 2010b; 2011a). The global results of the topographic and crust components 
stripping gravity corrections and the step-wise consolidated crust-stripped gravity data were presented and discussed in Tenzer et al. (2009b, 2012b). Tenzer et al. (2011b) demonstrated that the consolidated crust-stripped gravity disturbances are significantly correlated with the Moho geometry; the correlation coefficient between these two quantities is 0.96 ; see also Tenzer et al. (2009b). The GRS-80 (Moritz, 1990) normal gravity field is typically considered in computing the gravity disturbances. Alternatively, more complex Earth's model can be adopted, such as the Preliminary Reference Earth Model (PREM; Dziewonski and Anderson, 1981).

Introducing the radial integral kernel function $K$ as

$K\left(r, \psi, D^{\prime}\right)=-\int_{r^{\prime}=\mathrm{R}-D^{\prime}}^{\mathrm{R}} \frac{\partial \ell^{-1}\left(r, \psi, r^{\prime}\right)}{\partial r} r^{\prime 2} \mathrm{~d} r^{\prime}$,

Equation (1) becomes

$\delta g^{c s}(r, \Omega)=\mathrm{G} \iint_{\Omega^{\prime} \in \Phi} \Delta \rho^{\mathrm{c} / \mathrm{m}}\left(\Omega^{\prime}\right) K\left(r, \psi, D^{\prime}\right) \mathrm{d} \Omega^{\prime}$,

where $D\left(\Omega^{\prime}\right) \equiv D^{\prime}$. The expression in Eq. (3) is a non-linear Fredholm integral equation of the first kind. Its linearization is done by applying the Taylor series with respect to the Moho depth values $D^{\prime}$, while disregarding the higher than first-order terms. The relative linearization errors in Eq. (3) are of order $\sim 1 \times 10^{-3}$. Tenzer et al. (2012b) estimated that relative uncertainties in the computed values of the consolidated crust-stripped gravity disturbances $\delta g^{c s}$ can reach $\sim 10 \%$. The linearization errors are thus completely negligible. The linearization yields

$\delta g^{c s}(r, \Omega) \cong g^{i}(r, \Omega)+\mathrm{G} \iint_{\Omega^{\prime} \in \Phi} \Delta \rho^{\mathrm{c} / \mathrm{m}}\left(\Omega^{\prime}\right) \frac{\partial}{\partial D^{\prime}} K\left(r, \psi, D^{\prime}\right) \delta D^{\prime} \mathrm{d} \Omega^{\prime}$,

where $\delta D^{\prime}$ is the (differential) Moho depth correction. The compensation attraction $g^{i}$ in Eq. (4) is computed from the a priori (initial) Moho depths $D_{0}^{\prime}$ (using, for instance, the CRUST1.0 Moho depths) according to the following expression

$$
\begin{aligned}
g^{i}(r, \Omega) & =-\mathrm{G} \iint_{\Omega^{\prime} \in \Phi} \Delta \rho^{\mathrm{c} / \mathrm{m}}\left(\Omega^{\prime}\right) \int_{r^{\prime}=\mathrm{R}-D_{0}^{\prime}}^{\mathrm{R}} \frac{\partial \ell^{-1}\left(r, \psi, r^{\prime}\right)}{\partial r} r^{\prime 2} \mathrm{~d} r^{\prime} \mathrm{d} \Omega^{\prime}= \\
& =\mathrm{G} \iint_{\Omega^{\prime} \in \Phi} \Delta \rho^{\mathrm{c} / \mathrm{m}}\left(\Omega^{\prime}\right) K\left(r, \psi, D_{0}^{\prime}\right) \mathrm{d} \Omega^{\prime} .
\end{aligned}
$$


It is assumed that the values of the Moho density contrast $\Delta \rho^{\mathrm{c} / \mathrm{m}}$ in Eq. (5) are a priori known (e.g., from the CRUST1.0). We further define the complete crust-stripped (relative to the upper mantle lateral density) isostatic gravity disturbance $\delta g^{m}$ as (Tenzer et al., 2012b)

$\delta g^{m}(r, \Omega)=\delta g^{c s}(r, \Omega)-g^{i}(r, \Omega)$.

Inserting from Eq. (6) back to Eq. (4), we get

$\delta g^{m}(r, \Omega)=\mathrm{G} \iint_{\Omega^{\prime} \in \Phi} \Delta \rho^{\mathrm{c} / \mathrm{m}}\left(\Omega^{\prime}\right) \mathrm{T}\left(r, \psi, D^{\prime}\right) \delta D^{\prime} \mathrm{d} \Omega^{\prime}$,

where

$\mathrm{T}\left(r, \psi, D^{\prime}\right)=\frac{\partial}{\partial D^{\prime}} \mathrm{K}\left(r, \psi, D^{\prime}\right)$.

The linearized integral equation in Eq. (7) defines the relation between the input gravity data $\delta g^{m}$ and the unknown (and sought) Moho correction terms $\delta D^{\prime}$. These correction terms are found based on solving the gravimetric inverse problem. The application of $\delta D^{\prime}$ to the a priori (initial) Moho model $D_{0}^{\prime}$ yields the final result $D^{\prime}$; i.e., $D^{\prime}=D_{0}^{\prime}+\delta D^{\prime}$.

\section{Spectral form of integral kernels $\mathrm{K}$ and $\mathrm{T}$}

The spectral representation of the reciprocal spatial distance $\ell^{-1}$ for the external convergence domain $r \geq \mathrm{R}$ (and $r^{\prime}<\mathrm{R}$ ) reads (e.g. Heiskanen and Moritz, 1967)

$\ell^{-1}\left(r, \psi, r^{\prime}\right)=\frac{1}{r} \sum_{n=0}^{\infty}\left(\frac{r^{\prime}}{r}\right)^{n} P_{n}(t)$,

where $\mathrm{P}_{\mathrm{n}}$ is the Legendre polynomial of degree $n$ with argument $t=\cos \psi$; $\cos \psi=\sin \phi \sin \phi^{\prime}+\cos \phi \cos \phi^{\prime} \cos \left(\lambda^{\prime}-\lambda\right)$. From Eq. (9), the radial derivative of $\ell^{-1}$ is found to be

$\frac{\partial \ell^{-1}\left(r, \psi, r^{\prime}\right)}{\partial r}=-\frac{1}{r^{\prime 2}} \sum_{n=0}^{\infty}\left(\frac{r^{\prime}}{r}\right)^{n+2}(n+1) \mathrm{P}_{\mathrm{n}}(t)$. 
Substitution from Eq. (10) to Eq. (2) yields

$K\left(r, \psi, D^{\prime}\right)=\int_{r^{\prime}=\mathrm{R}-D^{\prime}}^{\mathrm{R}} \sum_{n=0}^{\infty}\left(\frac{r^{\prime}}{r}\right)^{n+2}(n+1) \mathrm{P}_{\mathrm{n}}(t) \mathrm{d} r^{\prime}$.

Solving the integral of $K$ in Eq. (11), we get

$K\left(r, \psi, D^{\prime}\right)=\left.r \sum_{n=0}^{\infty}\left(\frac{r^{\prime}}{r}\right)^{n+3} \frac{n+1}{n+3} \mathrm{P}_{\mathrm{n}}(t)\right|_{r^{\prime}=\mathrm{R}-D^{\prime}} ^{\mathrm{R}}$.

After substituting for the integral limits in Eq. (12), we arrive at

$K\left(r, \psi, D^{\prime}\right)=r \sum_{n=0}^{\infty}\left(\frac{\mathrm{R}}{r}\right)^{n+3}\left[1-\left(1-\frac{D^{\prime}}{\mathrm{R}}\right)^{n+3}\right] \frac{n+1}{n+3} \mathrm{P}_{\mathrm{n}}(t)$.

Inserting for $\mathrm{K}$ in Eq. (8) from Eq. (13) and solving the radial derivative, the spectral representation of the integral kernel $\mathrm{T}$ is found to be

$$
\begin{aligned}
\mathrm{T}\left(r, \psi, D^{\prime}\right) & =\frac{\partial \mathrm{K}}{\partial D^{\prime}}=r \sum_{n=0}^{\infty}\left(\frac{\mathrm{R}}{r}\right)^{n+3} \frac{\partial}{\partial D^{\prime}}\left[1-\left(1-\frac{D^{\prime}}{\mathrm{R}}\right)^{n+3}\right] \frac{n+1}{n+3} \mathrm{P}_{\mathrm{n}}(t)= \\
& =\sum_{n=0}^{\infty}\left(\frac{\mathrm{R}}{r}\right)^{n+2} \frac{(n+1)(n+3)}{n+3} \mathrm{P}_{\mathrm{n}}(t)\left(1-\frac{D^{\prime}}{\mathrm{R}}\right)^{n+2}= \\
& =\sum_{n=0}^{\infty}\left(\frac{\mathrm{R}-D^{\prime}}{r}\right)^{n+2}(n+1) \mathrm{P}_{\mathrm{n}}(t)
\end{aligned}
$$

Denoting $\tau=\left(\mathrm{R}-D^{\prime}\right) / r$, Eq. (14) is finally rewritten as

$\mathrm{T}(t, \tau)=\sum_{n=0}^{\infty} \tau^{n+2}(n+1) \mathrm{P}_{\mathrm{n}}(t)$.

If the input gravity data $\delta g^{m}$ at the surface points are downward continued to sea level in prior of solving the gravimetric inverse problem, the kernel $\mathrm{T}$ becomes

$\mathrm{T}\left(t, \tau_{0}\right)=\sum_{n=0}^{\infty} \tau_{0}^{n+2}(n+1) \mathrm{P}_{\mathrm{n}}(t)$ 
where $\tau_{0}=1-D^{\prime} / \mathrm{R}$.

The integral kernel $\mathrm{T}\left(t, \tau_{0}\right)$ has a singularity for $\tau_{0} \rightarrow 1 \wedge t \rightarrow 1$. However, this singularity does not occur in the numerical solution because $D^{\prime}>0$. For $t=1\left(\tau_{0}<1\right): \mathrm{T}\left(1, \tau_{0}\right)=\tau_{0}^{2}\left(1-\tau_{0}\right)^{-2}$.

\section{Spectral model of the gravimetric inverse problem}

The input gravity data in the linearized integral equation (Eq. 7) of solving the gravimetric inverse problem are formed by the complete crust-stripped isostatic gravity disturbances $\delta g^{m}$. These gravity data are obtained from $\delta g^{c s}$ after applying the compensation attraction $g^{i}$ relative to the lateral density of the upper mantle (Eq. 5). As already stated this stripping gravity correction is computed from a priori Moho model (and using a variable density contrast of the Moho interface). This gravitational contribution thus represents the initial Moho geometry with respect to which the Moho corrections are solved for. Whereas the consolidated crust-stripped gravity disturbances $\delta g^{c s}$ should have a maximum correlation with the Moho geometry, the complete crust-stripped isostatic gravity disturbances $\delta g^{m}$ should have (theoretically) a minimum correlation with the Moho geometry, especially if the initial Moho model closely approximates the final gravimetric Moho solution. However, the gravitational signals of the deep mantle heterogeneities (including the core-mantle boundary) are still present in these refined gravity data. In the absence of a reliable 3-D global mantle model, this gravitational contribution can be treated in the spectral domain by subtracting a long-wavelength part of gravity spectrum (to a certain degree of spherical harmonics) from the isostatic gravity field spectrum.

From Eq. (15), the spectral representation of the integral kernel $\mathrm{T}(t, \tau)$ is given by

$\mathrm{T}(t, \tau)=\sum_{n=0}^{\infty}\left(\frac{\mathrm{R}}{r}\right)^{n+2}(n+1)\left(1-\frac{D^{\prime}}{\mathrm{R}}\right)^{n+2} \mathrm{P}_{\mathrm{n}}(t)$.

Substituting from Eq. (17) to the integral equation in Eq. (7), we arrive at

$$
\begin{aligned}
\delta g^{m}(r, \Omega) & =\mathrm{G} \sum_{n=0}^{\infty}\left(\frac{\mathrm{R}}{r}\right)^{n+2}(n+1) \iint_{\Omega^{\prime} \in \Phi} \Delta \rho^{\mathrm{c} / \mathrm{m}}\left(\Omega^{\prime}\right)\left(1-\frac{D^{\prime}}{\mathrm{R}}\right)^{n+2} \times \\
& \times \mathrm{P}_{\mathrm{n}}(t) \delta D^{\prime} \mathrm{d} \Omega^{\prime} .
\end{aligned}
$$


Since the expansion of the integral kernel $\mathrm{T}(t, \tau)$ into a series of spherical functions converges uniformly for the external domain $r>\mathrm{R}$, the interchange of summation and integration in Eq. (18) is permissible (cf. Moritz, 1990). The application of the binomial theorem to the term $\left(1-D^{\prime} / \mathrm{R}\right)^{n+2}$ on the right-hand side of Eq. (18) yields

$$
\left(1-\frac{D^{\prime}}{\mathrm{R}}\right)^{n+2} \cong \sum_{k=0}^{n+2}\left(\begin{array}{l}
n+2 \\
k
\end{array}\right) \frac{(-1)^{k}}{\mathrm{R}^{k}} D^{\prime k} .
$$

Inserting from Eq. (19) back to Eq. (18), we get

$$
\begin{aligned}
\delta g^{m}(r, \Omega) & =\mathrm{G} \sum_{n=0}^{\infty}\left(\frac{\mathrm{R}}{r}\right)^{n+2}(n+1) \times \\
& \times \sum_{k=0}^{n+2}\left(\begin{array}{l}
n+2 \\
k
\end{array}\right) \frac{(-1)^{k}}{\mathrm{R}^{k}} \iint_{\Omega^{\prime} \in \Phi} \Delta \rho^{\mathrm{c} / \mathrm{m}}\left(\Omega^{\prime}\right) D^{\prime k} \delta D^{\prime} \mathrm{P}_{\mathrm{n}}(t) \mathrm{d} \Omega^{\prime} .
\end{aligned}
$$

We further define the Moho-correction spherical function $\delta \mathrm{M}_{\mathrm{n}}$ of degree $n$ as

$$
\begin{aligned}
\delta \mathrm{M}_{\mathrm{n}}(\Omega) & =\frac{2 n+1}{4 \pi} \iint_{\Omega^{\prime} \in \Phi} \Delta \rho^{\mathrm{c} / \mathrm{m}}\left(\Omega^{\prime}\right) D^{\prime} \delta D^{\prime} \mathrm{P}_{\mathrm{n}}(t) \mathrm{d} \Omega^{\prime}= \\
& =\sum_{\mathrm{m}=-\mathrm{n}}^{\mathrm{n}} \delta \mathrm{M}_{\mathrm{n}, \mathrm{m}} \mathrm{Y}_{\mathrm{n}, \mathrm{m}}(\Omega),
\end{aligned}
$$

where $Y_{\mathrm{n}, \mathrm{m}}$ are the (fully-normalized) surface spherical harmonic functions of degree $n$ and order $m$, and $\delta \mathrm{M}_{\mathrm{n}, \mathrm{m}}$ are the Moho corrections coefficients. The corresponding higher-order terms $\left\{\delta \mathrm{M}_{\mathrm{n}}^{(\mathrm{k})}: k=2,3,4, \ldots\right\}$ read

$$
\begin{aligned}
\delta \mathrm{M}_{\mathrm{n}}^{(\mathrm{k})}(\Omega) & =\frac{2 n+1}{4 \pi} \iint_{\Omega^{\prime} \in \Phi} \Delta \rho^{\mathrm{c} / \mathrm{m}}\left(\Omega^{\prime}\right) D^{\prime k} \delta D^{\prime} \mathrm{P}_{\mathrm{n}}(t) \mathrm{d} \Omega^{\prime}= \\
& =\sum_{\mathrm{m}=-\mathrm{n}}^{\mathrm{n}} \delta \mathrm{M}_{\mathrm{n}, \mathrm{m}}^{(\mathrm{k})} \mathrm{Y}_{\mathrm{n}, \mathrm{m}}(\Omega) .
\end{aligned}
$$

From Eqs. (20-22), we get

$$
\delta g^{m}(r, \Omega)=4 \pi \mathrm{G} \sum_{n=0}^{\infty}\left(\frac{\mathrm{R}}{r}\right)^{n+2} \frac{n+1}{2 n+1} \times
$$




$$
\times \sum_{k=0}^{n+2}\left(\begin{array}{l}
n+2 \\
k
\end{array}\right) \frac{(-1)^{k}}{\mathrm{R}^{k}} \sum_{\mathrm{m}=-\mathrm{n}}^{\mathrm{n}} \delta \mathrm{M}_{\mathrm{n}, \mathrm{m}}^{(\mathrm{k})} \mathrm{Y}_{\mathrm{n}, \mathrm{m}}(\Omega) .
$$

To relate the spherical functions $\delta \mathrm{M}_{\mathrm{n}}$ (and their higher-order terms) with spherical harmonics, which describe the Earth's gravity field, the constituents on the right-hand side of Eq. (22) are scaled by the geocentric gravitational constant GM $=3986005 \times 10^{8} \mathrm{~m}^{3} \mathrm{~s}^{-2}$. For the spherical approximation, the geocentric gravitational constant is given by (e.g., Novák, 2010)

$\mathrm{GM}=\frac{4 \pi}{3} \mathrm{GR}^{3} \bar{\rho}^{\text {Earth }}$,

where $\bar{\rho}^{\text {Earth }}=5500 \mathrm{~kg} \mathrm{~m}^{-3}$ is the Earth's mean mass density.

Combining Eqs. (23) and (24) and limiting the spectral solution to a certain interval $N_{\min } \leq n \leq N_{\max }$ of spherical harmonics, we get

$\delta g^{m}(r, \Omega)=\frac{\mathrm{GM}}{\mathrm{R}^{2}} \sum_{n=N_{\min }}^{N_{\max }}\left(\frac{\mathrm{R}}{r}\right)^{n+2}(n+1) \sum_{\mathrm{m}=-\mathrm{n}}^{\mathrm{n}} F_{\mathrm{n}, \mathrm{m}}^{\delta \mathrm{M}} \mathrm{Y}_{\mathrm{n}, \mathrm{m}}(\Omega)$,

where $N_{\min }$ and $N_{\max }$ are the lower and upper summation indexes respectively. The numerical coefficients $F_{\mathrm{n}, \mathrm{m}}^{\delta \mathrm{M}}$ are given by

$F_{\mathrm{n}, \mathrm{m}}^{\delta \mathrm{M}}=\frac{1}{2 n+1} \frac{3}{\bar{\rho}^{\text {Earth }}} \sum_{k=0}^{n+2}\left(\begin{array}{l}n+2 \\ k\end{array}\right) \frac{(-1)^{k}}{\mathrm{R}^{k+1}} \delta \mathrm{M}_{\mathrm{n}, \mathrm{m}}^{(\mathrm{k})}$.

The gravimetric inverse problem in Eq. (25) can be simplified by assuming only a constant value of the Moho density contrast $\Delta \rho^{\mathrm{c} / \mathrm{m}}$. Hence

$\delta g^{m}(r, \Omega)=\frac{\mathrm{GM}}{\mathrm{R}^{2}} \sum_{n=N_{\min }}^{N_{\max }}\left(\frac{\mathrm{R}}{r}\right)^{n+2}(n+1) \sum_{\mathrm{m}=-\mathrm{n}}^{\mathrm{n}} F_{\mathrm{n}, \mathrm{m}}^{\delta \mathrm{D}} \mathrm{Y}_{\mathrm{n}, \mathrm{m}}(\Omega)$,

where the coefficients $F_{\mathrm{n}, \mathrm{m}}^{\delta \mathrm{D}}$ read

$F_{\mathrm{n}, \mathrm{m}}^{\delta \mathrm{D}}=\frac{3}{2 n+1} \frac{\Delta \rho^{\mathrm{c} / \mathrm{m}}}{\bar{\rho}^{\mathrm{Earth}}} \sum_{k=0}^{n+2}\left(\begin{array}{l}n+2 \\ k\end{array}\right) \frac{(-1)^{k}}{\mathrm{R}^{k+1}} \delta \mathrm{D}_{\mathrm{n}, \mathrm{m}}^{(\mathrm{k})}$. 
The coefficients $\delta \mathrm{D}_{\mathrm{n}, \mathrm{m}}$ and their higher-order terms $\left\{\delta \mathrm{D}_{\mathrm{n}, \mathrm{m}}^{(\mathrm{k})}: k=2,3,4, \ldots\right\}$ are defined as follows

$$
\begin{aligned}
\delta \mathrm{D}_{\mathrm{n}}^{(\mathrm{k})}(\Omega) & =\frac{2 n+1}{4 \pi} \iint_{\Omega^{\prime} \in \Phi} D^{\prime k} \delta D^{\prime} \mathrm{P}_{\mathrm{n}}(t) \mathrm{d} \Omega^{\prime}= \\
& =\sum_{\mathrm{m}=-\mathrm{n}}^{\mathrm{n}} \delta \mathrm{D}_{\mathrm{n}, \mathrm{m}}^{(\mathrm{k})} \mathrm{Y}_{\mathrm{n}, \mathrm{m}}(\Omega) .
\end{aligned}
$$

The lower summation index $N_{\text {min }}$ in Eqs. (25) and (27) determines the maximum degree of spherical harmonics, which should be removed from the input gravity field. It is expected that a subtracted long-wavelength gravity contribution is attributed mainly to the mantle structure and the core-mantle boundary. However, our current knowledge about the spatial mantle density structure is restricted by the lack of reliable global data. A possible way how to estimate the degree $N_{\min }$ of long-wavelength spherical harmonic terms which should be removed from the gravity field was given by Eckhardt (1983). The principle of this procedure is based on finding the representative depth of gravity signal attributed to each spherical harmonic degree term. The spherical harmonics which have the depth below a certain limit (chosen, for instance, as the maximum Moho depth) are removed from the gravity field. Nonetheless, the complete subtraction of the gravity signal from the mantle density structure using this procedure is questionable, because there is hardly any unique spectral distinction between the long-wavelength gravity signal from the mantle and the expected higherfrequency signal of the Moho geometry. Tenzer et al. (2012b) demonstrated the presence of significant correlation $(>0.6)$ between the mantle gravity signal and the Moho geometry at the medium gravity spectrum (between 60 and 90 of spherical harmonics degree terms). On the other hand, the gravity signal of the core-mantle boundary could be completely subtracted from the refined gravity data as it is fully attributed to a long-wavelength part of gravity field.

\section{Model uncertainties}

The expected largest uncertainties in the estimated Moho depths are mainly due to inaccuracies of crustal models currently available. As stated before, 
the relative errors in computed values of the consolidated crust-stripped gravity data can reach $\sim 10 \%$ (Tenzer et al., 2012b). The global models of the Earth's gravity field, topography, ice, and bathymetry have a relatively high resolution and accuracy. The computation of the gravity data, which are corrected for the gravitational contributions of these density components can thus be done with a sufficient accuracy. On the other hand, the datasets of the spatial density distribution of sediments and consolidated (crystalline) crust have a low accuracy and resolution (i.e., the CRUST1.0 data). The computation of respective gravity corrections and corrected gravity data is thus restricted especially over large parts of the world where these data are not available or their accuracy and resolution are very low. $\check{C} a d e k$ and Martinec (1991) estimated uncertainties of the Moho depths in their global crustal thickness model to be $\sim 20 \%(5 \mathrm{~km})$ for the oceanic crust and of $\sim 10 \%(3 \mathrm{~km})$ for the continental crust. The results of more recent seismic and gravity studies, however, revealed that these error estimates are too optimistic. Grad et al. (2009), for instance, demonstrated that the Moho uncertainties (estimated based on processing the seismic data) under the Europe regionally exceed $10 \mathrm{~km}$ with the average error of more than $4 \mathrm{~km}$. Much larger Moho uncertainties are expected over large parts of the world where the seismic data are sparse.

Similarly as uncertainties in the input gravity data, the errors in the Moho density contrast propagate proportionally to the errors in the estimated Moho depths. In regional studies covering areas with a relatively homogenous lithospheric structure, the constant value of the Moho density contrast can be adopted. There are several methods of treating the Moho density contrast in regional isostatic solutions. The most commonly used approach is based on the best fitting of the regional isostatic solution to seismic data. Steffen et al. (2011), for instance, applied this principle to model the Moho depths beneath Tien Shan. The assumption of a constant Moho density contrast, however, might not be sufficient in global gravimetric studies. As discussed in Introduction, results of seismic and gravity studies confirmed large variations of the Moho density contrast. Consequently, this assumption might yields large errors in the estimated global Moho depths. For this reason, the functional model for finding the Moho depths was formulated under the assumption that the variable Moho density contrast is a priori known from global seismic models. 


\section{Summary and concluding remarks}

The gravimetric inverse problem for a determination of the Moho geometry was derived by adopting a generalized crustal compensation model. This compensation model assumes a variable depth and density of compensation. The functional relation between the gravity data and the (unknown) Moho depths was established by means of the (non-linear) Fredholm integral equation of the first kind (Eq. 3). This functional relation takes into consideration the variable Moho density contrast. The gravity data in this functional model should have (theoretically) a maximum correlation with the (a priori) Moho geometry. The linearization was applied by means of incorporating the adopted compensation model (Eq. 4) which should minimize the correlation between the input gravity data and the Moho geometry. The solution to the gravimetric inverse problem was derived in a frequency domain.

This functional model facilitates all available information on the density distribution within the crust and mantle. In the absence of a reliable 3-D mantle density model, we took into consideration only the major known crustal and upper mantle density structures (available from seismic surveys). Whereas in classical isostatic models the isostatic mass balance is established based on a particular hypothesis about the crustal density structure, this model takes into consideration also the density structure of the upper mantle. This is done practically by assuming a variable density contrast at the Moho interface in the computation of the compensation attraction (Eq. 5) and formulation of the linearized observation equation (Eq. 7). Moreover, this functional model allows treating the (unknown) deep mantle heterogeneities (including the core-mantle boundary) in a spectral domain by excluding the long-wavelength spherical functions (to a certain degree) directly from the functional model (Eq. 25).

Formulation of the functional model in a spectral domain allows the selection of a maximum degree of spherical harmonics used in solving the inverse problem. In this way, the gravimetric forward modelling of the gravity field quantities is realized only up a maximum degree of spherical harmonics which contain the signature of the Moho geometry, while a high-frequency part of the gravity spectrum (which comprises mainly a signal from shallow crustal density structures) is disregarded. 


\section{References}

Airy G. B., 1855: On the computations of the effect of the attraction of the mountain masses as disturbing the apparent astronomical latitude of stations in geodetic surveys. Trans. Roy. Soc. (London), ser. B, 145.

Bassin C., Laske G., Masters T. G., 2000: The current limits of resolution for surface wave tomography in North America, EOS Trans AGU, 81, F897.

Bagherbandi M., Sjöberg L. E., 2012: Non-isostatic effects on crustal thickness: A study using CRUST2.0 in Fennoscandia, Phys. Earth Planet. Inter., 200-201, 37-44.

Braitenberg C., Zadro M., 1999: Iterative 3D gravity inversion with integration of seismologic data. Boll. Geof. Teor. Appl., 40, 3/4, 469-476.

Braitenberg C., Wienecke S., Wang Y., 2006: Basement structures from satellite-derived gravity field: south China Sea ridge. J. Geophys. Res., 111, B05407.

Braitenberg C., Mariani P., Reguzzoni M., Ussami N., 2010: GOCE observations for detecting unknown tectonic features. In: Proc. of the ESA Living Planet Symposium, 28 June - 2, July 2010, Bergen, Norway, ESA SP-686.

Cadek O., Martinec Z., 1991: Spherical harmonic expansion of the earth's crustal thickness up to degree and order 30. Studia Geophys. Geodaet., 35, 151-165.

Dorman L. M., Lewis T. R., 1970: Experimental Isostasy. In: 2. An isostatic model for the U.S.A. derived from gravity and topographic data. J. Geophys. Res., 75, $3367-3386$.

Dziewonski A. M., Anderson D. L., 1981: Preliminary reference Earth model. Phys. Earth Plan. Int., 25, 297-356.

Eckhardt D. H., 1983: The gains of small circular, square and rectangular filters for surface waves on a sphere. Bull. Geod., 57, 394-409.

Geiss E., 1987: A new compilation of crustal thickness data for the Mediterranean area. Ann. Geophys., 5B, 623-630.

Grad M., Tiira T., ESC Working Group, 2009: The Moho depth map of the European Plate. Geophys. J. Int., 176, 1, 279-292.

Hayford J. F., 1909: The figure of the earth and isostasy from measurements in the United States. USCGS.

Hayford J. F., Bowie W., 1912: The effect of topography and isostatic compensation upon the intensity of gravity. USCGS, Spec. Publ., No. 10.

Heiskanen W. A., Vening Meinesz F. A., 1958: The Earth and its Gravity Field. McGrawHill Book Company, Inc.

Heiskanen W. A., Moritz H., 1967: Physical Geodesy. Freeman W. H., New York.

Kaban M. K., Schwintzer P., Tikhotsky S. A., 1999: Global isostatic gravity model of the Earth. Geophys. J. Int., 136, 519-536.

Kaban M. K., Schwintzer P., Artemieva I. M., Mooney W. D., 2003: Density of the continental roots: compositional and thermal contributions. Earth Planet. Sci. Lett., 209, 53-69.

Kaban M. K., Schwintzer P., Reigber Ch., 2004: A new isostatic model of the lithosphere and gravity field. J. Geod., 78, 368-385. 
Makhloof A., 2007: The use of topographic-isostatic mass information in geodetic applications. Doctoral dissertation, Dept. of Theoretical and Physical Geodesy, Bonn, Germany.

Martinec Z., 1994: The minimum depth of compensation of topographic masses. Geophys. J. Int., 117, 545-554.

Meier U., Curtis A., Trampert J., 2007: Global crustal thickness from neural network inversion of surface wave data. Geophys. J. Int., $\overline{\mathbf{1}} \mathbf{6 9}, \overline{706}-\overline{7} 22$.

Mooney W. D., Laske G., Masters T. G., 1998: CRUST 5.1: a global crustal model at $5 \times 5$ deg. J. Geophys. Res., 103, 727-747.

Moritz H., 1990: The figure of the Earth. Wichmann H., Karlsruhe.

Nataf H. C., Ricard Y., 1996: 3SMAC: An a priori tomographic model of the upper mantle based on geophysical modeling. Phys. Earth Planet. Int., 95, 101-122.

Novák P., 2010: High resolution constituents of the Earth gravitational field. Surv. Geoph., 31, 1, 1-21.

Oldenburg D. W., 1974: The inversion and interpretation of gravity anomalies. Geophysics, 39, 526-536.

Pratt J. H., 1855: On the attraction of the Himalaya Mountains and of the elevated regions beyond upon the plumb-line in India. Trans. Roy. Soc. (London), Ser. B, 145.

Sampietro D., 2011: GOCE exploitation for Moho modeling and applications. In: Proc. of the $4^{\text {th }}$ International GOCE User Workshop, 31 March - 1 April 2011, Munich, Germany.

Sampietro D., Reguzzoni M., Braitenberg C., 2013: The GOCE estimated Moho beneath the Tibetan Plateau and Himalaya. In: International Association of Geodesy Symposia, Earth on the Edge: Science for a Sustainable Planet, Proceedings of the IAG General Assembly, 28 June - 2 July 2011, Melbourne, Australia, Rizos, C. and P. Willis (Eds.), 139, Springer-Verlag, Berlin.

Shapiro N. M., Ritzwoller M. H., 2002: Monte-Carlo inversion for a global shear-velocity model of the crust and upper mantle. Geophys. J. Int., 151, 88-105.

Sjöberg L. E., 2009: Solving Vening Meinesz-Moritz Inverse Problem in Isostasy. Geophys. J. Int., 179, 3, 1527-1536.

Sjöberg L. E., Bagherbandi M., 2011: A Method of Estimating the Moho Density Contrast with a Tentative Application by EGM08 and CRUST2.0. Acta Geophys., 58, 1-24.

Soller D. R., Richard D. R., Richard D. B., 1982: A new global crustal thickness map. Tectonics, 1, 145-149.

Steffen R., Steffen H., Jentzsch G., 2011: A three-dimensional Moho depth model for the Tien Shan from EGM2008 gravity data, Tectonics, 30, TC5019.

Tenzer R., Hamayun, Vajda P., 2008: Global map of the gravity anomaly corrected for complete effects of the topography, and of density contrasts of global ocean, ice, and sediments. Contrib. Geophys. Geod., 38, 4, 357-370.

Tenzer R., Hamayun, Vajda P., 2009a: Global maps of the CRUST2.0 crustal components stripped gravity disturbances. J. Geophys. Res., 114, B, 05408. 
Tenzer R., Hamayun, Vajda P., 2009b: A global correlation of the step-wise consolidated crust-stripped gravity field quantities with the topography, bathymetry, and the CRUST2.0 Moho boundary. Contrib. Geophys. Geod., 39, 2, 133-147.

Tenzer R., Vajda P., Hamayun, 2010a: A mathematical model of the bathymetry-generated external gravitational field. Contrib. Geophys. Geod., 40, 1, 31-44.

Tenzer R., Abdalla A., Vajda P., Hamayun, 2010b: The spherical harmonic representation of the gravitational field quantities generated by the ice density contrast. Contrib. Geophys. Geod., 40, 3, 207-223.

Tenzer R., Novák P., Gladkikh V., 2011a: On the accuracy of the bathymetry-generated gravitational field quantities for a depth-dependent seawater density distribution. Studia Geophys. Geodaet., 55, 4, 609-626.

Tenzer R., Hamayun, Novák P., Gladkikh V., Vajda P., 2011b: Global crust-mantle density contrast estimated from EGM2008, DTM2008, CRUST2.0, and ICE-5G. Pure Appl. Geophys., doi:10.1007/s00024-011-0410-3.

Tenzer R., Novák P., Vajda P., Gladkikh V., Hamayun, 2012a: Spectral harmonic analysis and synthesis of Earth's crust gravity field. Comput. Geosc., 16, 1, 193-207.

Tenzer R., Gladkikh V., Vajda P., Novák P., 2012b: Spatial and spectral analysis of refined gravity data for modelling the crust-mantle interface and mantle-lithosphere structure. Surveys in Geophysics, 33, 5, 817-839.

Tsoulis D., 2004: Spherical harmonic analysis of the CRUST2.0 global crustal model. J. Geod., 78, 1-2, 7-11.

Vajda P., Vaníček P., Novák P., Tenzer R., Ellmann A., 2007: Secondary indirect effects in gravity anomaly data inversion or interpretation. J. Geophys. Res., 112, B6, B06411, 1-13, doi:10.1029/2006JB004470.

Vening Meinesz F. A., 1931: Une nouvelle méthode pour la réduction isostatique régionale de l'intensité de la pesanteur. Bull. Geod., 29, 33-51.

Watts A. B., 2001: Isostasy and flexure of the lithosphere, Cambridge University Press, Cambridge.

Wienecke S., Braitenberg C., Götze H.-J., 2007: A new analytical solution estimating the flexural rigidity in the Central Andes. Geophys. J. Int., 169, 3, 789-794.

Wild F., Heck B., 2004: Effects of topographic and isostatic masses in satellite gravity gradiometry. In: Proc. Second International GOCE User Workshop GOCE. The Geoid and Oceanography, ESA-ESRIN, Frascati, Italy, March 8-10, 2004 (ESA SP569, June 2004), CD-ROM. 